\title{
Enhancing organizational performance in the telecommunication industry in Saudi Arabia
}

\author{
Yuen Yee Yen $^{a^{*}}$, Ahmed Jafar Salleh Shatta ${ }^{a}$ and Elsadig Musa Ahmad ${ }^{\mathrm{a}}$
}

${ }^{a}$ Multimedia University, Malaysia

\section{H R O N I C L E}

\section{Article history:}

Received: July 20, 2020

Received in revised format:

September 102020

Accepted: October 5, 2020

Available online:

October 8, 2020

\section{Keywords:}

Knowledge management

Telecommunication industry

Organizational performance

\section{A B S T R A C T}

The aim of this study is to provide an insight into the factors that influence the successful implementation of knowledge management and organizational performance in Saudi Arabia's telecommunications industry. One thousand copies of survey questionnaires were sent to targeted telecommunication organization and they were distributed by hand. Middle management level was chosen to participate in this study due to their importance as stressed by many knowledge management researchers. Out of the 1000 questionnaires distributed, 441 complete questionnaires were successfully collected and used for data analysis. There is still a lack of the knowledge management research in the Saudi Arabia context. The present research focuses on telecommunication industry in Saudi Arabia. The result of this research will be able to provide an insight into what are the overall perception overall perception of knowledge management and how various knowledge management elements (preliminary success factors, strategies and processes) affect the successful implementation of knowledge management and its organizational performance among the telecommunication organizations in Saudi Arabia. The findings are useful for the telecommunication industry. The present research serves as one of the pioneer studies that focuses on telecommunication industry in Saudi Arabia. The empirical insights from this study contributes to successful implementation of knowledge management in the telecommunication industry in Saudi Arabia.

\section{Introduction}

The shifting winds of change in today's business environment, have enabled the telecommunication industry in Saudi Arabia to realize that knowledge is their key asset as the marketplace is increasingly competitive and the rate of innovation is rising together with the pressure of the emergence of a global knowledge-based economy. Also, in today's global market place, competitive advantage no longer comes exclusively from efficient methods of production and delivery; it also derives from leveraging knowledge (Fey \& Furu, 2008). In this knowledge-based economy, every industry can be considered global, and every organization, knowledge-based. In Phelps et al. (2012)'s survey on business executives, 69\% of respondents reported plans to use knowledge management as a tool for growth in the upcoming year. According to the knowledge-based view of the firm, knowledge-based assets create value, making knowledge a source of competitive advantage (Fey \& Furu, 2008; Wang \& Noe, 2010). Very few studies have been conducted so far to investigate the level of knowledge management implementation in this growing, yet competitive industry. Wang and Noe (2010) revealed that $90.2 \%$ of the respondents in telecommunication industry would like to undertake researches in the domain of knowledge management on organizational level. However, there is a gap between the perceived importance of knowledge management factors and their implementation. The key focus of this paper is to identify the impact of knowledge management on organizations performance in the telecommunication industry in Saudi Arabia. Therefore, the present research has proposed benchmarking, culture, empowerment, innovation, leadership, reward, teamwork and training. Moreover, this study also intends to examine the effect of knowledge management factors (benchmarking, culture, empowerment, innovation, leadership, reward, teamwork and training) on knowledge capturing and storing. This research is significant for several reasons. First, it fills a research gap about the

* Corresponding author.

E-mail address: yyyuen@mmu.edu.my (Y. Yee Yen) 
knowledge management in Saudi Arabia. It aims to identify the factors that are important for the success of knowledge management implementation. Prior studies indicated that the importance of knowledge management in telecommunication industry in. Up to date, there is still a lack of knowledge management research in the Saudi Arabia context (Chang et al., 2012; Xu et al., 2013). Therefore, there is a need for this research to be conducted in Saudi Arabia. The present research serves as one of the pioneer studies that focuses on telecommunication industry in Saudi Arabia. The result of this research will be able to provide an insight into what are the overall perception overall perception of knowledge management and how various knowledge management elements (preliminary success factors, strategies and processes) affect the successful implementation of knowledge management among the telecommunication organizations in Saudi Arabia. The aim of this study is to provide an insight into the factors that influence the successful implementation of knowledge management and organizational performance in Saudi Arabia's telecommunication industry. The findings may also be useful to the telecommunication industry. This paper therefore provides an opportunity to the practitioners to undergo a self-check regarding the various important knowledge management areas it covers. For academics and students, the empirical insights from this study may add to the knowledge on the relationships between various factors affecting the successful implementation of knowledge management in the telecommunication industry in Saudi Arabia and their impact on the organizations. This may aid in a better understanding of the pre-requisites necessary to succeed in the telecommunication industry, especially in today's competitive environment.

This paper is divided into four sections and the list of references and appendices. The first section is introduction that identifies the problem, the importance of the study the objectives of the study, the developed set of research questions of the study. The second section reviewed the literature review that includes the theoretical framework and thorough insight of previously conducted studies in this field. The third section describes the methodology and procedures of the study, results of the study are presented and discussed in the fourth section and discussed in the fifth section.

\section{Literature review}

There has been very little study in telecommunication industry in Saudi Arabia that clearly defines boundaries and frameworks of knowledge management. Because knowledge management involves almost every field of business, the proposed success factors are fragmented and diversified. Moreover, many studies (Černe et al., 2014; Connelly et al., 2012; Paulin \& Suneson, 2015; Wang et al. 2010) are narrowly scoped although they identify some critical success factors. There is limited number of studies on organizational performance and knowledge management in Saudi Arabia context, one of the limited studies, Michailova and Mustaffa (2012) analyzed the impact of knowledge management on multinational organizations and the findings showed that an effective increase in the knowledge management is needed for better organizational performance (Soud Jaradat \& Al Maani, 2014). A number of studies (Carlson \& 2012; Herdman Witherspoon et al., 2013; Zhang et al., 2014) have been conducted to identify the factors that may influence implementation of knowledge sharing practices or in other words implementation of knowledge management in organizations. Successful implementation of knowledge management depends on the principal climate of the organization and the law and procedures being prevailing in it. It means that successful implementation of the phenomenon heavily depends on the culture of the organization, the quality of its employees and their behaviors (Luo \& Lee, 2013). Another paper assesses the factors, which analyze the readiness of an organization to adopt knowledge management implementation. According to Jaradat, and Al Maani (2014), the technology infrastructure, the readiness of the process of the knowledge management implementation process are important to affect organization's decision to implement knowledge management process. These factors are then sub-divided into further roots such as to have a good technology structure it is very important for the human resource to be used to of that infrastructure. Otherwise, it may result into serious losses (Mojibi, Khojasteh \& Khojasteh-Ghamari, 2015). Interestingly, transformational leadership to have relationship with knowledge management practices (Le \& Lei, 2019; Singh et al., 2019). It is because such kind of leadership tends to nurture harmony, trust and unity among the employees of the organization. When leadership values are inculcated (Le \& Lei, 2019), it ultimately helps organizational performance to bloom and makes it ready for the upcoming challenges and innovations like that of knowledge management practices (Yaghoubi, Mahallati, Safari Moghadam \& Rahimi, 2014). In the light of above literature, it can be concluded that no matter how diverse the cultures are within the world but there still is a room for adopting knowledge management. Knowledge management factors identified from the above literature can be implemented in the telecommunication industry in Saudi Arabia as well for example good technology infrastructure, employees training and developing knowledge databases. However, factors like those of transformational leadership and employee turnover needs attention as far as Saudi Arabia culture is concerned.

\section{Research framework development}

The review of literature indicates that there are many factors that have been identified which contribute to the successful implementation of knowledge management in organization. It is also clear that the important factors affecting the success of knowledge management implementation should be those that have been researched by various disciplines. However, these variables were studied independently and therefore, there is an absence of unifying theories on what factors contribute to the successful implementation of knowledge management in organizations. In other words, there was no attempt to integrate all the important factors that are associated with the success of knowledge management implementation particularly in the Saudi Arabia context. Since knowledge management is an emerging field, there has been one single set of widely recognized and empirically validated criteria for evaluating the success of knowledge management implementation. 
Many of past studies (Černe et al., 2014; Connelly et al., 2012; Paulin \& Suneson, 2015; Wang et al. 2010) are conducted theoretically and in isolation, that is none of them are integrated within a single framework. Therefore, in line with the trend towards examining more, fully integrated models of the knowledge management success factors contribute to the performance of the organization. In addition, since there is little statistical evidence that the proposed factors affect the success of knowledge management implementations these factors need to be tested systematically and empirically. This study is one of the pioneer research in Saudi Arabia that integrates all knowledge management factors to be tested against the organization performance especially in the Saudi Arabia in telecommunication industry. The current study aims to integrate and empirically test all these important knowledge management factors identified from the literature that contribute to the successful implementation of knowledge management among Saudi Arabia in Telecommunication industry within a single framework and to investigate their possible associations with organizational performance. Based on the theoretical framework, a research framework was developed to guide the current study. This framework integrates all the factors identified in the literature and serves as blue print for the current study. The knowledge management factors consist of employee training, empowerment, teamwork, leadership, reward, benchmarking, egalitarian culture and innovation. These factors have also been found to have associations with the dependent variable (Organizational Performance).

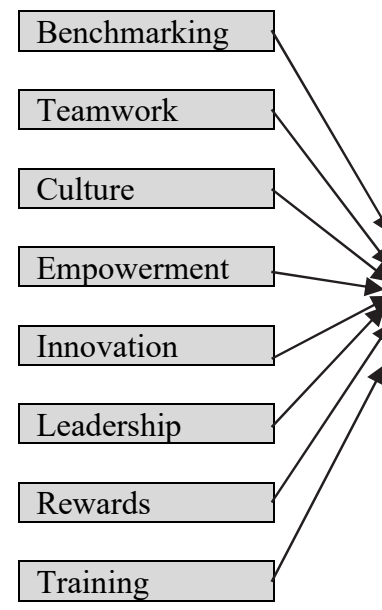

\section{Research methodology}

The review of literature on the subject indicates that there are many factors that have been identified which contribute to the successful implementation of knowledge management in organization. It is also clear that the important factors affecting the success of knowledge management implementation should be those that have been researched by various disciplines. However, these variables were studied independently and therefore, there is an absence of unifying theories on what factors contribute to the successful implementation of knowledge management in organizations. There is no attempt to integrate all the important factors that are associated with the success of knowledge management implementation particularly in the Saudi Arabia context. Since knowledge management is an emerging field, there has been one single set of widely recognized and empirically validated criteria for evaluating the success of knowledge management implementation. Target respondents in this study were middle management from various functional areas in Saudi Arabia telecommunication organizations. The population telecommunication organizations came from three categories, line providers manufacturers of mobile phones and application service providers. The list of organizations was obtained from the official list of telecommunication organizations in Saudi Arabia available at government agency. These organizations are located in the areas of Jeddah and Riyadh. Ninety percent of the telecommunication organizations are located in these big cities of Saudi Arabia. They consist of multinational organizations as well as local organizations. As a rule set for this study, the organizations must be involved in any one of the three categories mentioned above in order to be qualified for this study. Retailers of telecommunication organizations were excluded in the sample as they are considered very small scale. It is not feasible for them to implement knowledge management at this stage. Human resource managers of these targeted organizations were contacted to get approval to distribute the questionnaires in their organizations. Finally, 1000 copies of survey questionnaires were then sent to each targeted telecommunication organization and they were distributed by hand. All the questionnaires were distributed to middle management level from different functional departments in the organizations. Completed questionnaires were then sent back by mail to the researcher. The questionnaire targeted knowledge workers at middle management level. Middle management level was chosen to participate in this study due to their importance as stressed by many knowledge management researchers. Out of the 1000 questionnaires distributed, 441 complete questionnaires were successfully collected and used for data analysis. The good response from the organizations was also due to the personal contact approach used by the researcher. The researcher had contacted personally all the human resource managers and convinced them of the needs and the benefits of the study. A series of follow-up calls were made. It is felt that the good response rate is adequate to offer grounds for establishing reliability and generality of the findings. 


\section{Data analysis}

The hypotheses of the present study were tested by applying Partial Least Squares (PLS) using Smart PLS Version 3.0 of the total 441 respondents. The main function of the PLS-PM is to maximize the variance of dependent variable in fundamental path models (Hair et al, 2016). Moreover, (PLS) could detect the predictive relationships among the latent variables by performing the statistical analysis. The path model gives a picture of the hypotheses in the research framework as all of the arrows of the path model are only one direction and single-headed (Hair et al. 2016). Thus, PLS has the greatest essence in measuring the predictive relationships of the research framework. Nonparametric bootstrapping (Wetzels, Odekerken-Schroder, \& van Oppen, 2009) with 5,000 replications was then applied. PLS comprises of two sub-models namely the measurement model and structural model. The structural models composed of the causal relationships between latent constructs, whereas the measurement model composed of the relationships among indicators and their corresponding constructs. There are two types of variables in structural model namely exogenous (independent) and endogenous (dependent) latent variables. In the present study measurement model analysis was used to assess construct validity and internal consistency reliability. Convergent and discriminant validity comprise construct validity. Furthermore, by examining path coefficients $(\beta)$ and their significant levels by means of PLS path modelling by applying a non-parametric bootstrapping procedure (Chin, 1998; Henseler et al., 2009), the structural model and hypotheses were assessed. In addition to the assessment of path coefficient, as suggested by Hair et al. (2014), three criteria need to be tested in examining the structural model, as follows: coefficient of determination $\left(\mathrm{R}^{2}\right)$, effect size $\left(\mathrm{f}^{2}\right)$, and predictive relevance $\left(\mathrm{Q}^{2}\right)$. PLS has five main steps as an instrument of the research analysis namely the validity and reliability of measurement model, the model fit, the direct and indirect effects, the moderating effect of deal proneness and the moderating effect of age is tested using multi-group analysis (MGA).

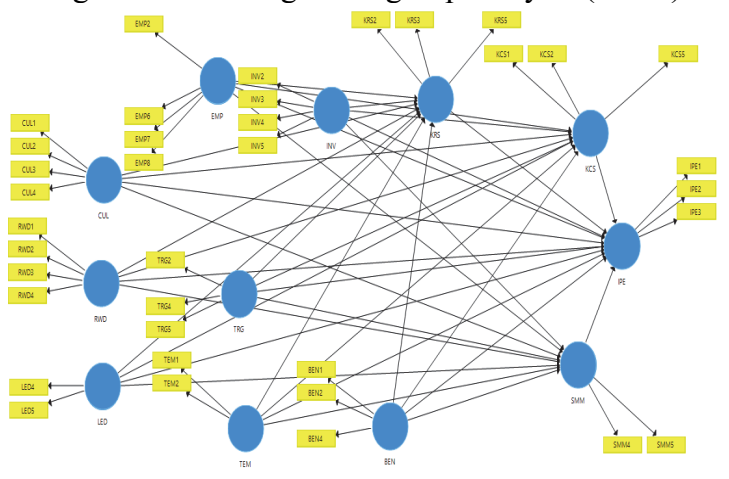

Table 1

Fig. 2. Data Analysis Results

Path Coefficient and Hypothesis Testing (Direct Effect)

\begin{tabular}{|c|c|c|c|c|c|}
\hline Hypothesis & Relationships & Path Coefficient & Std. Error & t-value & Decision \\
\hline \multicolumn{6}{|c|}{ Effect on Knowledge Capturing and Storing (KCS) } \\
\hline H1a & $\mathrm{BEN} \rightarrow \mathrm{KCS}$ & 0.160 & 0.057 & $2.792 * *$ & Supported \\
\hline $\mathrm{H} 1 \mathrm{~b}$ & $\mathrm{CUL} \rightarrow \mathrm{KCS}$ & -0.003 & 0.072 & 0.047 & Not supported \\
\hline H1c & $\mathrm{EMP} \rightarrow \mathrm{KCS}$ & 0.011 & 0.085 & 0.131 & Not supported \\
\hline H1d & $\mathrm{INV} \rightarrow \mathrm{KCS}$ & 0.035 & 0.063 & 0.549 & Not supported \\
\hline H1e & $\mathrm{LED} \rightarrow \mathrm{KCS}$ & 0.044 & 0.072 & 0.605 & Not supported \\
\hline H1f & $\mathrm{RWD} \rightarrow \mathrm{KCS}$ & 0.023 & 0.071 & 0.328 & Not supported \\
\hline $\mathrm{H} 1 \mathrm{~g}$ & $\mathrm{TEM} \rightarrow \mathrm{KCS}$ & 0.210 & 0.059 & $3.587 * * *$ & Supported \\
\hline $\mathrm{H} 1 \mathrm{~h}$ & $\mathrm{TRG} \rightarrow \mathrm{KCS}$ & 0.193 & 0.068 & $2.842^{* *}$ & Supported \\
\hline \multicolumn{6}{|c|}{ Effect on Knowledge Reusing and Sharing (KRS) } \\
\hline $\mathrm{H} 2 \mathrm{a}$ & $\mathrm{BEN} \rightarrow \mathrm{KRS}$ & 0.047 & 0.057 & 0.824 & Not supported \\
\hline $\mathrm{H} 2 \mathrm{~b}$ & $\mathrm{CUL} \rightarrow \mathrm{KRS}$ & 0.037 & 0.080 & 0.460 & Not supported \\
\hline $\mathrm{H} 2 \mathrm{c}$ & $\mathrm{EMP} \rightarrow \mathrm{KRS}$ & -0.178 & 0.085 & $2.106^{*}$ & Supported \\
\hline $\mathrm{H} 2 \mathrm{~d}$ & $\mathrm{INV} \rightarrow \mathrm{KRS}$ & 0.070 & 0.057 & 1.224 & Not supported \\
\hline $\mathrm{H} 2 \mathrm{e}$ & $\mathrm{LED} \rightarrow \mathrm{KRS}$ & 0.052 & 0.062 & 0.837 & Not supported \\
\hline $\mathrm{H} 2 \mathrm{f}$ & $\mathrm{RWD} \rightarrow \mathrm{KRS}$ & 0.091 & 0.070 & 1.301 & Not supported \\
\hline $\mathrm{H} 2 \mathrm{~g}$ & $\mathrm{TEM} \rightarrow \mathrm{KRS}$ & 0.213 & 0.070 & $3.060 * *$ & Supported \\
\hline $\mathrm{H} 2 \mathrm{~h}$ & $\mathrm{TRG} \rightarrow \mathrm{KRS}$ & 0.210 & 0.063 & $3.344 * *$ & Supported \\
\hline \multicolumn{6}{|c|}{ Effect On System Maintaining and Monitoring (SMM) } \\
\hline $\mathrm{H} 3 \mathrm{a}$ & $\mathrm{BEN} \rightarrow \mathrm{SMM}$ & 0.139 & 0.061 & $2.287^{*}$ & Supported \\
\hline $\mathrm{H} 3 \mathrm{~b}$ & $\mathrm{CUL} \rightarrow \mathrm{SMM}$ & 0.138 & 0.075 & $1.833^{*}$ & Supported \\
\hline $\mathrm{H} 3 \mathrm{c}$ & $\mathrm{EMP} \rightarrow \mathrm{SMM}$ & -0.104 & 0.090 & 1.159 & Not supported \\
\hline $\mathrm{H} 3 \mathrm{~d}$ & $\mathrm{INV} \rightarrow \mathrm{SMM}$ & 0.055 & 0.060 & 0.928 & Not supported \\
\hline $\mathrm{H} 3 \mathrm{e}$ & $\mathrm{LED} \rightarrow \mathrm{SMM}$ & 0.121 & 0.056 & $2.174^{*}$ & Supported \\
\hline $\mathrm{H} 3 \mathrm{f}$ & $\mathrm{RWD} \rightarrow \mathrm{SMM}$ & 0.107 & 0.069 & 1.561 & Not supported \\
\hline $\mathrm{H} 3 \mathrm{~g}$ & $\mathrm{TEM} \rightarrow \mathrm{SMM}$ & 0.102 & 0.059 & $1.725^{*}$ & Supported \\
\hline $\mathrm{H} 3 \mathrm{~h}$ & $\mathrm{TRG} \rightarrow \mathrm{SMM}$ & 0.121 & 0.064 & $1.903^{*}$ & Supported \\
\hline \multicolumn{6}{|c|}{ Effect on Organizational Performance (IPE) } \\
\hline $\mathrm{H} 4 \mathrm{a}$ & $\mathrm{KCS} \rightarrow \mathrm{IPE}$ & 0.027 & 0.050 & 0.530 & Not supported \\
\hline $\mathrm{H} 4 \mathrm{~b}$ & $\mathrm{KRS} \rightarrow \mathrm{IPE}$ & 0.116 & 0.056 & $2.078^{*}$ & Supported \\
\hline $\mathrm{H} 4 \mathrm{c}$ & $\mathrm{SMM} \rightarrow \mathrm{IPE}$ & 0.293 & 0.049 & $5.932 * * *$ & Supported \\
\hline
\end{tabular}


Fig. 2 and Table 1 show the significance of direct path coefficients and hypotheses. Regarding the effect on knowledge capturing and storing, the results demonstrate that benchmarking $(\beta=0.160, p<0.01)$, teamwork $(\beta=0.210, p<0.001)$, and training $(\beta=0.193, p<0.001)$, are the only significant path coefficients on knowledge capturing and storing. Meanwhile, culture $(\beta=0.072, p>0.05)$, empowerment $(\beta=0.011, p>0.05)$, innovation $(\beta=0.035, p>0.05)$, leadership $(\beta=0.044, p>0.05)$ and reward $(\beta=0.023, p>0.05)$ have no effect on knowledge capturing and storing. Thus, these results supporting H1a, H1g, and $\mathrm{H} 1 \mathrm{~h}$, however, not supporting hypotheses H1b, H1c, H1d, H1e, and H1f. Concerning the effect on knowledge reusing and sharing, the results show that empowerment $(\beta=0.178, p<0.05)$, teamwork $(\beta=0.213, \mathrm{p}<0.01)$, and training $(\beta=0.210, p<0.01)$ have significant effects on knowledge reusing and sharing. Meanwhile, benchmarking $(\beta=0.047, p>0.05)$, culture $(\beta=0.037$, $p>0.05)$, innovation $(\beta=0.070, p>0.05)$, leadership $(\beta=0.052, p>0.05)$, and reward $(\beta=0.091, p>0.05)$ have no effect. Therefore, these results supporting hypotheses $\mathrm{H} 2 \mathrm{c}, \mathrm{H} 2 \mathrm{~g}$, and $\mathrm{H} 2 \mathrm{~h}$ whereas, $\mathrm{H} 2 \mathrm{a}, \mathrm{H} 2 \mathrm{~b}, \mathrm{H} 2 \mathrm{~d}, \mathrm{H} 2 \mathrm{e}$, and $\mathrm{H} 2 \mathrm{f}$ not supported. For the effect on system maintaining and monitoring the results in Table 4.8 show that benchmarking $(\beta=0.139, p<0.05)$, culture $(\beta=0.138, p<0.05)$, leadership $(\beta=0.121, p<0.05)$, teamwork $(\beta=0.102, p<0.05)$ and training $(\beta=0.121, p<0.05)$ has a significant effect on system maintaining and monitoring. Whereas, empowerment $\beta=-0.104, p>0.05)$, innovation $\beta=0.055, p>0.05$ ), and reward $\beta=0.0107, p>0.05$ ) has no effect and thus, H3a, H3b, H3e, H3g, and H3h are supported while H3c, H3d and H3f not supported. The results in Table 1 reveal that the effects of knowledge reusing and sharing $(\beta=0.116, p<0.05)$, and system maintaining and monitoring $(\beta=0.293, p<0.001)$ on institution performance are significant and positive. However, the effect of knowledge capturing and storing $(\beta=0.027, p>0.05)$ on institution performance are not significant. Therefore, these results supporting only $\mathrm{H} 4 \mathrm{~b}$, and $\mathrm{H} 4 \mathrm{c}$, however, it is not supporting $\mathrm{H} 4 \mathrm{a}$

\section{Discussion and recommendation}

A very important finding of this study is that in telecommunication organizations in Saudi Arabia, employees are not empowered and might not be ready for effective involvement. Telecommunication organizations in Saudi Arabia management is based on the management by objectives approach and employees seem not ready to take the responsibility of unassigned jobs, which makes it difficult to nurture the knowledge management implementation in the organization. The finding of study also reveals that leadership has no significant impact on knowledge capturing and storing as well as knowledge reusing and sharing. Since the leadership in telecommunication companies still do not provide full information to employees and do not listen to employee problems, this limits knowledge capturing and storing as well as knowledge reusing and sharing activities among employees or between employees and supervisors. Surprisingly, reward is also not an important factor to improve on knowledge capturing and storing, knowledge reusing and sharing and system maintaining and monitoring in telecommunication companies in Saudi Arabia because some employees are reluctant to share their experience and knowledge due to the competition among labors. Telecommunication organizations are lack of innovation capability because employees are not willing to contribute their ideas in product design and development due to the fear of losing superiority even though rewards are provided. In order to improve organizational performance in Saudi Arabia, innovation, empowerment, leadership and rewards system are important attributes that should be considered for successful knowledge management initiative. Absence of these important factors can hinder exchanging of knowledge within the context of telecommunication organizations in Saudi Arabia. The results of the study suggest that by promoting a culture, that supports teamwork and information flow between workers, an organization can enhance the knowledge capturing, storing, reusing and sharing between its workers. Successful knowledge management initiative, telecommunication organizations in Saudi Arabia management has to promote a culture and innovation of involvement where employees are encouraged to make decisions that affect their jobs. In its attempt to initiate and practice knowledge management, management of telecommunication organizations in Saudi Arabia should clearly understand that knowledge management theories that have been applied in other cultural settings might not be applicable for Saudi Arabia culture due to cultural differences that impose certain organizational characteristics. Therefore, managers have to accurately assess the knowledge management of their organization. Some cultural changes should be introduced. According to this study, these changes might include encouraging of knowledge capturing, storing, reusing and sharing through the creation of a rewards-orientation culture, more effective information flow, promoting an empowerment environment, and encouraging innovation to create new knowledge. These cultural changes must begin with the senior management and must be an important part of the organizational values system. Effective reward system for employees should develop a conducive knowledge sharing culture and achieve valuable knowledge capturing, storing, reusing and sharing. Knowledge sharing and exchanging has to be practiced by telecommunication in Saudi Arabia by building this culture using deferent techniques like training, meeting, building communities of practices. Moreover, organizations must take steps to facilitate the integration process between individuals and organizational interests. Employees also should be able to interact freely with each other, which can enrich their training and teamwork and leadership to change. Encouraging and facilitating the organizational communities of practice seems essential towards exchanging of knowledge.

\section{Practical contribution}

The results of this study could be useful for the management of telecommunication industry in Saudi Arabia to establish implementing knowledge management system. It identifies important considerations and ideas knowledge capturing and storing, knowledge reusing and storing and system maintenance and monitoring. Telecommunication organizations in Saudi Arabia and suitability for a generally successful and useful knowledge management initiative in knowledge creation and knowledge reusing and storing and system maintenance and monitoring. This study is helpful for managers to learn how to develop knowledge management strategies It seeks to overcome the obstacles of knowledge management in telecommunication organizations in Saudi Arabia. This study highlights the importance of benchmark and leadership characteristics and their 
impact on organizational performance. Bearing in mind the scarcity of available studies in the context of the Arab countries. The questionnaire used in the current study to examine the hypotheses only provided a cross-section of the research in nature, which is the limitation of this study.

\section{Conclusion}

The main objective of the current study is to assess the effect of knowledge management factors (benchmarking, culture, empowerment, innovation, leadership, reward and training) on the performance of telecommunication organizations in Saudi Arabia. In view of the literature review, findings of the study and the observation during conducting the field survey, this present research has identified recommendations for policymakers. The present study mainly focused on telecommunication sector, thus further studies are needed to assess the relationship between knowledge management factors and organizational performance in public sector. Due to the resource and time constraint, the current study has investigated the effect of knowledge management factors on institution performance among only telecommunication organizations. Thus, future researchers have to extend this study by including other industries in Saudi Arabia.

\section{References}

Carlson, K. D., \& Herdman, A. O. (2012). Understanding the impact of convergent validity on research results. Organizational Research Methods, 15(1), 17-32.

Černe, M., Nerstad, C. G., Dysvik, A., \& Škerlavaj, M. (2014). What goes around comes around: Knowledge hiding, perceived motivational climate, and creativity. Academy of Management Journal, 57(1), 172-192.

Chang, Y. Y., Gong, Y., \& Peng, M. W. (2012). Expatriate knowledge transfer, subsidiary absorptive capacity, and subsidiary performance. Academy of Management Journal, 55(4), 927-948.

Connelly, C. E., Zweig, D., Webster, J., \& Trougakos, J. P. (2012). Knowledge hiding in organizations. Journal of Organizational behavior, 33(1), 64-88.

Fey, C. F., \& Furu, P. (2008). Top management incentive compensation and knowledge sharing in multinational corporations. Strategic Management Journal, 29(12), 1301-1323.

Jaradat, N. M. S., \& Al Maani, A. I. (2014). The impact of knowledge management infrastructure on performance effectiveness in Jordanian organizations. Arab Economic and Business Journal, 9(1), 27-36.

Le, P. B., \& Lei, H. (2019). Determinants of innovation capability: the roles of transformational leadership, knowledge sharing and perceived organizational support. Journal of Knowledge Management, 23(3), 527-547.

Luo, B., \& Lee, A. S. (2013). The critical roles of endoplasmic reticulum chaperones and unfolded protein response in tumorigenesis and anticancer therapies. Oncogene, 32(7), 805-818.

Michailova, S., \& Mustaffa, Z. (2012). Subsidiary knowledge flows in multinational corporations: Research accomplishments, gaps, and opportunities. Journal of World Business, 47(3), 383-396.

Mojibi, T., Khojasteh, Y., \& Khojasteh-Ghamari, Z. (2015). The role of infrastructure factors in knowledge management implementation. Knowledge and Process Management, 22(1), 34-40.

Paulin, D., \& Suneson, K. (2015). Knowledge transfer, knowledge sharing and knowledge barriers-three blurry terms in KM. Leading Issues in Knowledge Management, 2(2), 73.

Phelps, C., Heidl, R., \& Wadhwa, A. (2012). Knowledge, networks, and knowledge networks: A review and research agenda. Journal of Management, 38(4), 1115-1166.

Singh, S. K., Gupta, S., Busso, D., \& Kamboj, S. (2019). Top management knowledge value, knowledge sharing practices, open innovation and organizational performance. Journal of Business Research.

Wang, S., \& Noe, R. A. (2010). Knowledge sharing: A review and directions for future research. Human Resource Management Review, 20(2), 115-131.

Wang, S., Tomlinson, E. C., \& Noe, R. A. (2010). The role of mentor trust and protege internal locus of control in formal mentoring relationships. Journal of Applied Psychology, 95(2), 358.

Wang, Z., \& Wang, N. (2012). Knowledge sharing, innovation and firm performance. Expert Systems with Applications, 39(10), 8899-8908

Witherspoon, C. L., Bergner, J., Cockrell, C., \& Stone, D. N. (2013). Antecedents of organizational knowledge sharing: a metaanalysis and critique. Journal of Knowledge Management, 17(2), 250-277

$\mathrm{Xu}$, D., \& Meyer, K. E. (2013). Linking theory and context:'Strategy research in emerging economies' after Wright et al.(2005). Journal of Management Studies, 50(7), 1322-1346.

Yaghoubi H, Mahallati T, Safari Moghadam A, \& Rahimi E. (2014). Transformational leadership: Enabling factor of knowledge management practices. Journal of Management and Sustainability, 4(3).

Zhang, X., De Pablos, P. O., \& Xu, Q. (2014). Culture effects on the knowledge sharing in multi-national virtual classes: A mixed method. Computers in Human Behavior, 31, 491-498.

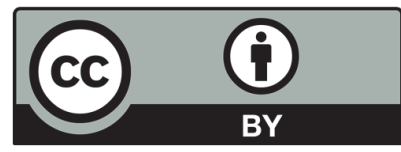

(C) 2021 by the authors; licensee Growing Science, Canada. This is an open access article distributed under the terms and conditions of the Creative Commons Attribution (CC-BY) license (http://creativecommons.org/licenses/by/4.0/). 